\title{
Regional and Gender Differences in the Cephalic Index among South Indian and North-East Indian Population
}

\author{
Mebin Wilson Thomas ${ }^{1}$, Santhosh Kareepadath Rajan ${ }^{2}$ \\ ${ }^{1}$ Assistant Professor, Department of Forensic Science, JAIN (Deemed to be University), Bangalore, Karnataka, \\ India, ${ }^{2}$ Assistant Professor, Department of Psychology, CHRIST (Deemed to be University), Bangalore, Karnataka, \\ India
}

\begin{abstract}
Background: Cephalic index has a wide range of scope in personal identification, plastic surgery, and orthodontics and in identifying the differences in race and ethnicity. The present research is an attempt to identify the difference in the cephalic index in association with region and gender in a sample of total 300 participants (South Indians, 150 and North East Indians, 150), with an equal number of males and females. Standardized spreading caliper was used to measure the head breadth and head length of each participant. Measurement of cephalic index was obtained using the equation; maximum cranial breadth/maximum cranial length multiplied by 100 .

Results: The baseline of the cephalic index of the participants from South India were approximated as 76.47, with a range of 71.27 to 81.67. The baseline of the participants from North East India can be approximated as 84.16 , with a range of 80.34 to 87.98 . The baseline indicated that participants from South India are more mesocephalic, and from North East India are more brachycephalic. Mann-Whitney U test indicated that there is a significant regional difference in the cephalic index. There is no significant gender difference. Conclusion:Generalization regarding the regional difference in cephalic index can be made by comparing the present results with the previous findings. The results contribute to forensic, anthropological, and clinical literature.
\end{abstract}

Keywords: Forensic Anthropology, Cephalic Index, South India, North India, Gender difference

\section{Introduction}

Evidence indicates a clear socio-demographic trend in the cephalic index and head shape ${ }^{1}$. In medico-legal and forensic domain, the differences in the cephalic index and head shapes in association withsocio-demographic factors including geographical area, gender, age, and race have significant importance ${ }^{2}$. Cephalic index, also known as cranial index, as defined by Swedish professor

\section{Corresponding Author:}

Mebin Wilson Thomas,

Assistant Professor, Department of Forensic Science, JAIN (Deemed to be University), Bangalore, Karnataka, India - 560027, Mobile: +918618567204, email: mebinforensic@gmail.com of Anatomy, Anders Retzius (1796-1860), is the ratio of biparietal diameter (BPD) to the occipitofrontal diameter (OFD) of the skull. In other words, it is the ratio of the maximum breadth of the bare skull to its maximum length multiplied by hundred. Retzius classified cephalic index as gentesdolichocephalae, individuals with elongated skull shape, and gentesbrachycephalae, those with short skull shape ${ }^{3}$.

Later, based on research findings, more classifications and numerical values were introduced by determining the ratio between maximum breadth and maximum length of the head ${ }^{4,5}$. Classification systems gave more accurate result in determining the diversity in human facial morphology (Table 1).Based on the classification systems, it is also possible to predict the 
genetic transmission from parents to offspring and siblings ${ }^{6}$. Studies indicate the relevance of the cephalic index to identify racial, ethnic, and gender differences.

Table 1:Head classification according to cephalic index

\begin{tabular}{|c|c|}
\hline Cephalic Index Classification & Range of Cephalic Index \\
\hline Ultradolichocephalic & $55.0-59.9$ \\
\hline Hyperdolichocephalic & $60.0-64.9$ \\
\hline Dolichocephalic & $65.0-74.9$ \\
\hline Mesocephalic & $75.0-79.9$ \\
\hline Brachycephalic & $80.0-84.9$ \\
\hline Hyperbrachycephalic & $85.0-89.9$ \\
\hline Ultrabrachycephalic & $90.0-94.9$ \\
\hline
\end{tabular}

Findings related to cephalic index and head shape benefits the area of forensic science and forensic anthropologyimmensely, which includes facial reconstruction of disputed identity ${ }^{7}$, determination ${ }^{8}$ and classification $^{9}$ of race and sex, and identification of an anonymous individual's geographical region ${ }^{10}$. According toFranco et $\mathrm{al}^{3}(2013)$, cephalometrics is also useful to study craniofacial growth. Their findings emphasized the role of skull morphology in determining the shape of the face.

Studies that compare the difference in cephalic index concerningregion and genderof the individuals using inferential statistics from India is limited. The present research aimed at identifying the difference in the cephalic index in association with region and gender. Based on the present sample, wedetermined a baseline value and assessedthe differencebetween South and North East Indians, of the cephalic index. The findings will contribute to forensic, anthropological, and clinical studies.

\section{Materials and Methods}

\section{Sample}

Data was collected from 300 participants, 150 each from South and North East India, with an equal number of males and females, using purposive sampling technique from different colleges in Bangalore during the period of November2019- January2020.Individuals with cranio-facial trauma were excluded. Individuals with age below 22 were also excluded, because only after this age cephalic index measurement remains constant ${ }^{11}$. To ensure the homogeneity, individuals between 23 and 28 were included in the sample.

\section{Procedure}

Before the data collection, the investigators individually met the participants, provided the appropriate information, clarified the doubts, and took the written informed consent. Subsequently, head breadth and head length from each subject were measured using a standardized spreading caliper (Figure 1). The values obtained were documented. All the measurements were taken with the subjects sitting on a chair, in a relaxed state, and head in an anatomical position. The cephalic index was measured using Hardlika's method.The head length was obtained from measuring from glabella (point above the nasal root between the eyebrows and intersected by midsagittal plane), and the most projecting point at the inion (distal-most point placed 
on the eternal occipital protuberance in the midsagittal plane) and breadth of the skull from measuring maximum transverse diameter between the two euryons (either of the lateral points marking the ends of the greatest transverse diameter of the skull)

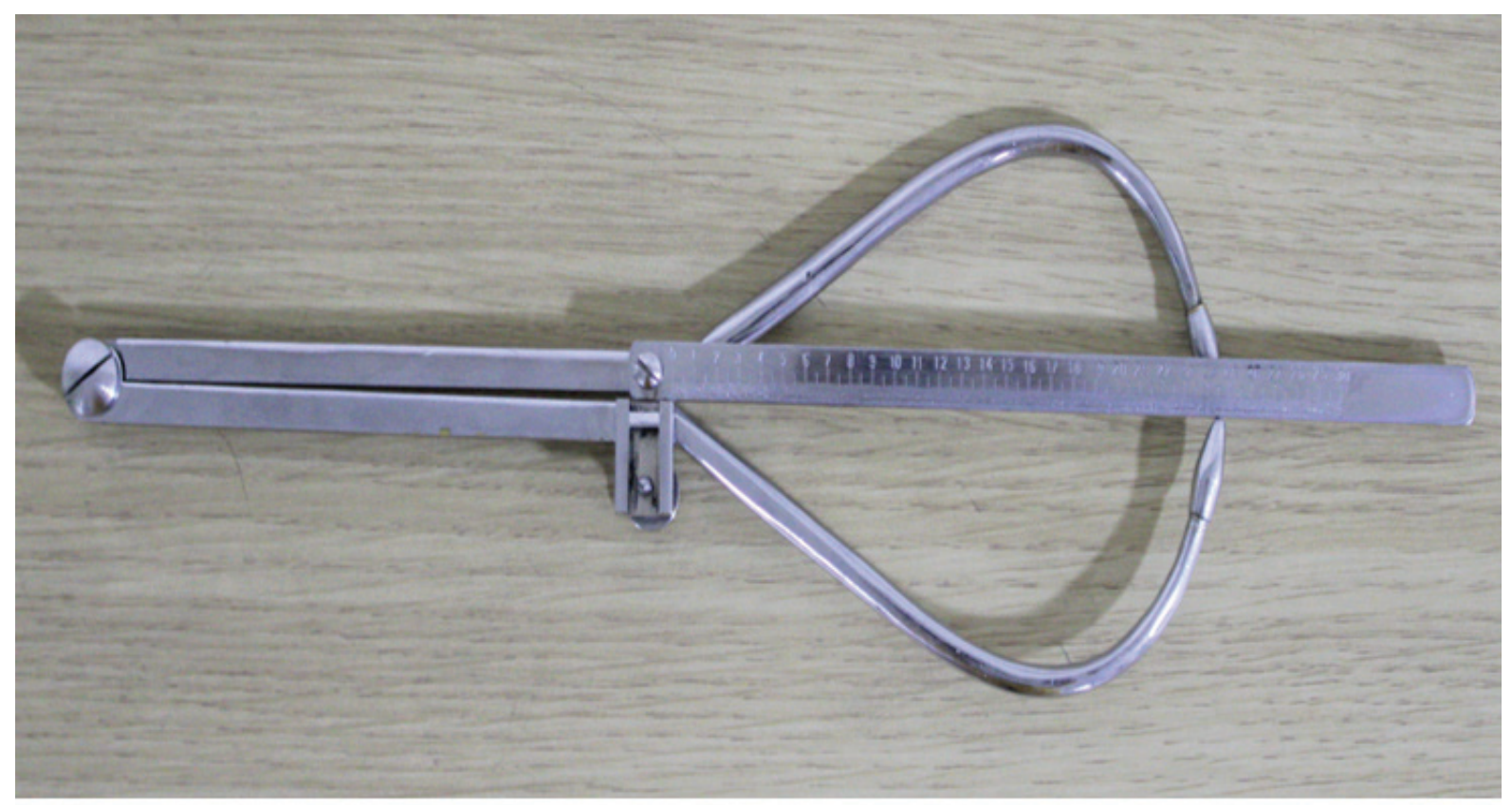

Figure 1: Spreading Caliper

\section{Measure}

The cephalic index was measured for each participant using the equation: Maximum cranial breadth/Maximum cranial length multiplied by 100. Readings were recorded by the investigators and repeated thrice on each subject to ensure authentication, and its mean value was considered for the analysis.

\section{Statistical Analysis}

Mean, and standard deviation was used to establish the baseline value of the cephalic index. Mann Whitney $\mathrm{U}$ test was used to analyze the difference in cephalic index between the groups.

\section{Results}

Table 2 summarizes the cross-tabulation of the participants concerning the cephalic index classification

Table 2: Cross tabulation which shows the distribution of the gender and cephalic index classification of the participants concerning the region

\begin{tabular}{|c|c|c|c|c|c|c|}
\hline \multirow{2}{*}{ Cephalic Index Classification } & \multicolumn{2}{|c|}{$\begin{array}{c}\text { South India } \\
(\mathbf{n}=\mathbf{1 5 0})\end{array}$} & \multicolumn{2}{|c|}{$\begin{array}{c}\text { North East India } \\
(\mathbf{n}=\mathbf{1 5 0})\end{array}$} & \multicolumn{2}{c|}{ Total (n=300) } \\
\cline { 2 - 7 } & $\begin{array}{c}\text { Male } \\
(\mathbf{n}=\mathbf{7 5})\end{array}$ & $\begin{array}{c}\text { Female } \\
(\mathbf{n}=\mathbf{7 5})\end{array}$ & $\begin{array}{c}\text { Male } \\
(\mathbf{n}=\mathbf{7 5})\end{array}$ & $\begin{array}{c}\text { Female } \\
(\mathbf{n}=75)\end{array}$ & South India & $\begin{array}{c}\text { North East } \\
\text { India }\end{array}$ \\
\hline Hyperdolichocephalic & 5 & 4 & 0 & 0 & $9(6.00 \%)$ & $0(0.00 \%)$ \\
\hline
\end{tabular}


Cont... Table 2: Cross tabulation which shows the distribution of the gender and cephalic index classification of the participants

\begin{tabular}{|c|c|c|c|c|c|c|}
\hline Dolichocephalic & 31 & 20 & 2 & 2 & $51(34.00 \%)$ & $4(2.67 \%)$ \\
\hline Mesocephalic & 29 & 30 & 9 & 5 & $59(39.33 \%)$ & $14(9.33 \%)$ \\
\hline Brachycephalic & 8 & 19 & 36 & 33 & $27(18.00 \%)$ & $69(46.00 \%)$ \\
\hline Hyperbrachycephalic & 0 & 2 & 26 & 35 & $2(1.33 \%)$ & $61(40.67 \%)$ \\
\hline Ultrabrachycephalic & 2 & 0 & 2 & 0 & $2(1.33 \%)$ & $2(1.33 \%)$ \\
\hline
\end{tabular}

Among the 150 participants from South India, $9(6 \%$, males $=5$, females $=4$ ) were hyperdolichocephalic, 51 $(34 \%$, males $=31$, females $=20)$ were dolichocephalic, 59 $(39.33 \%$, males $=29$, females $=30)$ were mesocephalic, $27(18 \%$, males $=8$, females $=19)$ were Brachycephalic, $2(1.33 \%$, females $=2)$ were hyperbrachycephalic, and
$2(1.33 \%$, males $=2)$ were ultrabrachycephalic. In the group of the North East Indians, 4 (2.67\%, males $=2$, females $=2)$ were dolichocephalic, $14(9.33 \%$, males $=9$, females $=5)$ were mesocephalic, $69(46 \%$, males $=36$, females $=33)$ were Brachycephalic, $61(40.67 \%$, males $=26$, females $=35$ ) were hyperbrachycephalic, and $2(1.33 \%$, males $=2)$ were ultrabrachycephalic.

Table 3: Mean and standard deviation ofcephalic index in the present sample

\begin{tabular}{|c|c|c|c|c|c|c|}
\hline \multirow{2}{*}{ Region } & \multicolumn{2}{|c|}{ Total } & \multicolumn{2}{c|}{ Males } & \multicolumn{2}{c|}{ Females } \\
\cline { 2 - 7 } & Mean & SD & Mean & SD & Mean & SD \\
\hline South India & 76.47 & 5.20 & 76.10 & 5.69 & 76.83 & 4.67 \\
\hline North East India & 84.16 & 3.82 & 83.61 & 3.96 & 84.71 & 3.63 \\
\hline
\end{tabular}

Mean cephalic index of the participants from South India was $76.47(\mathrm{SD}=5.20)$, with $76.10(\mathrm{SD}=5.69)$ for males, and $76.83(\mathrm{SD}=4.67)$ for females. Mean cephalic index of the participants from North East India was 84.16 $(\mathrm{SD}=3.82)$, with $83.61(\mathrm{SD}=3.96)$ for males, and $84.71(\mathrm{SD}=3.63)$ for females.

Table 4: Mann-Whitney $U$ test which shows the difference in cephalic index among the participants from South India $(\mathrm{N}=150)$ and North East India $(\mathrm{N}=150)$

\begin{tabular}{|c|c|c|c|c|c|}
\hline Variable & Region & Mean Rank & Median & U & Z \\
\hline \multirow{2}{*}{ Cephalic Index } & South India & 90.45 & 75.99 & \multirow{2}{*}{2242} & \multirow{2}{*}{$11.99^{* *}$} \\
\cline { 2 - 4 } & North East India & 210.55 & 84.62 & \\
\hline
\end{tabular}

$* * \mathrm{p}<.01$ 
Mann Whitney $U$ test showed a significant difference $(\mathrm{U}=2242, \mathrm{Z}=11.99, \mathrm{p}<.01)$ in cephalic index between the participants from South India and North East India.
Participants from North East India (Mean Rank $=210.55$, Median $=84.62$ ) have bigger cephalic index than those from South India (Mean Rank = 90.45, Median =75.99)

Table 5: Mann-Whitney $U$ test which shows the difference in cephalic index among the male $(N=75)$ and female $(N=$ 75) participants from South India

\begin{tabular}{|c|c|c|c|c|c|}
\hline \multirow{2}{*}{ Variable } & Gender & Mean Rank & Median & U & $\mathbf{Z}$ \\
\hline \multirow{2}{*}{ Cephalic Index } & Male & 69.32 & 75.71 & & \multirow{2}{*}{2349} \\
\cline { 2 - 5 } & Female & 81.68 & 76.44 & & 1.74 \\
\hline
\end{tabular}

Not Significant

Mann Whitney U test showed that male and female participants from South India have no significant difference in their cephalic index.

Table 6: Mann-Whitney $U$ test which shows the difference in cephalic index among the male $(N=75)$ and female $(N=$ 75) participants from North East India

\begin{tabular}{|c|c|c|c|c|c|}
\hline \multirow{2}{*}{ Variable } & Gender & Mean Rank & Median & $\mathbf{U}$ & $\mathbf{Z}$ \\
\hline \multirow{2}{*}{ Cephalic Index } & Male & 68.94 & 84.30 & \multirow{2}{*}{2320.5} & 1.85 \\
\cline { 2 - 4 } & Female & 82.06 & 84.91 & & \\
\hline
\end{tabular}

Not Significant

Mann Whitney U test showed that male and female participants from North East India have no significant difference in their cephalic index.

\section{Discussion}

Values from the cross-tabulation and percentage analysis showed that the majority of the participants from South India were dolichocephalicor mesocephalic. However, there were participants, even though comparatively lesser, who were classified as hyperdolichocephalic, brachycephalic, hyperbrachycephalic, and ultrabrachycephalic. There were no females in hyperbrachycephalic and no males in ultrabrachycephalic classifications. Previous studies hadalready revealed a high probability of individuals with Mesocephalic in different parts of India. For instance, the study by Nair, Anjankar, Singh, Bindra, and Satpathy ${ }^{12}$ (2014) in a sample of 480 medical students from central India showed that $43.58 \%$ males, as well as $42.93 \%$ females, were mesocephalic. Another study on 309 participants by Mishra, Tiwari, and Naik ${ }^{11}$ (2014), in an age group of 22 to 27, from Madhya Pradesh, also indicated the high prevalence of mesocephalics. Similar findings were reported from Odisha ${ }^{13}$, Andhra Pradesh ${ }^{14}$. However, a study by Kumari, Vijaya Babu, Kumari, and Nagamani ${ }^{15}$ (2015)in a sample of 280 participants from Vishakhapatnam showed more males as Mesocephalic, but more females as brachycephalic.

Among the North East Indian sample, there were no hyperdolichocephalics. Majority of the participants were Brachycephalics and hyperbrachycephalics. Participants classified as dolichocephalic, mesocephalic, and ultrabrachycephalic is comparatively lesser. There were no females in ultrabrachycephalic classification. A similar result was obtained by Byhndadaorili et $\mathrm{al}^{16}$ (2018)after researching seven different tribal 
population of north-eastern Indian states. Except for Garo population, predominant cephalic index of most of the tribal population in north-east were brachycephalic. Apart from this study, no other published literature could be found on the north-east population. However, studies conducted on different populations like Gujarati ${ }^{6,17}$, Punjabi $^{2,7}$, Bengali ${ }^{18}$ and Nepali ${ }^{19,20}$ indicateda predominance in brachycephaly.

It seems to be relevant to compare thepresent findings withthe documentation of Racial, Ethnic, Religious, and Linguistic Elements in Indian Population by Bhasin ${ }^{21}$ (2007). Bhasin, in her documentation, noted the classifications done by different researchers, including Risley (1915), Guha (1935) and Sarkar (1958/61). As per Risley's classification, Dolichocephalics were the inhabitants of Rajasthan, Punjab, Kashmir, Uttar Pradesh, Bihar, Andra Pradesh, and Madras. During the time of Risley, Guha, and Sarkar, Madras included Tamilnadu and about a half of Kerala. The other part of Kerala was named as Travancore-Cochin.Mesocephalics belonged to Bengal, Maharasthra, and Karnataka. Brachycephalicswere in Maharashtra, Bengal, Orissa, Nepal, Nagaland Assam, and Burma.In the observation of Risley, Dravidian, Aryo-Dravidian, and IndoAryan types were more Dolichocephalics. ScythoDravidian and Mongolo-Dravidian types include both Mesocephalics and Brachycehphalics. Mongoloid types were moreBrachychephalics. Risley's classification was criticized, mainly due to his techniques of measurement.

In Guha's observation, Dolichocephalics werethe inhabitants ofTamil Nadu, Kerala, Uttar Pradesh, Maharashtra, Bengal, Punjab, and in the Himalayan regions such as Assam and Nepal.They can be seen in Proto-Australoid, Mongoloid, Mediterranean, and Nordic classifications of Guha. Brachycephalics inhabited at Bhutan and Sikkim but had migrated through, Baluchistan, Sind, Gujarat, Maharashtra, Karnataka and then Sri Lanka. They can be seen in Alpinoids, Dinarics, Aremnoids, and Mongoloid classifications of Guha. According to Sarkar, Dolichocephalicswas in South India, Western India, Bihar, Orissa, Madya Pradesh;Mesocephalics, in Gujarat, Maharashtra, and
Karnataka; and Brachycephalics, in Extreme South along the coast of Chittagong hill tracts. The classifications of Australoids, Indo-Aryans and Mundary Speakers had more Dolichocephalics; Irano-Scythians had more Mesocephalics;far eastern, along with the cost of Chittagong hill tracts, had more Brachycephalics.

Closer scrutiny reveals a rough consistency in the observations of Risley, Guha, and Sarkar, at least in the comparisons of South India and North East. They are consistent in their observation of the prevalence of Dolichocephalics (Andra Pradesh, Tamil Nadu, and Kerala) and Mesocephalics (Karnataka) in South India, and Brachycephalics in the North East (Assam, andNagaland). However, we cannot neglect the inconsistencies in these three observations, which has happened at three different periods. Various factors might have played a role in this lack of consistency. Climatic condition is one of the critical factors that bring a change in the head size. According to Bharati, Som, Bharati, and Vasulu ${ }^{22}$ (2001), climatic conditions affect morphological features like stature, nose form, body build, and head form. Beals ${ }^{23}$ (1972) observed that Mesocephalic or brachycephalic is predominant in less hot regions and dolichocephalic, in hot climatic regions. Migrations and merging of different races through marriage or cohabitation can also result in the transformation in head size ${ }^{24}$.

In the present study, we identified a more massive presence of Hyperbrachycephalics among the North East Indian sample.This classification is new, and hence, Risley, Guha, and Sarkar have not mentioned it. Apart from this, we did a further specific analysis using mean and standard deviation to approximate a baseline and range of cephalic index of the participants from South India and North East India. The baseline of the cephalic index of the participants from South India can be approximated as 76.47 , with a range of 71.27 to 81.67 . The baseline of the participants from North East India can be approximated as 84.16 , with a range of 80.34 to 87.98 . The baseline indicated that participants from South India are more mesocephalic, and from North East India are more brachycephalic. This difference is 
confirmed to be significant using the Mann-Whitney U test. This baseline cannot be generalized as the sample is not representative. However, it could be taken as a reference to future research, which would attempt to establish a valid baseline.

Concerning gender, no significant difference could be identified between the participants from South India and North East India. This result contradicts with the previousfindings that showed sex or gender difference ${ }^{1,9}$. Probably males and females, born and brought up in the same geographical area, and from the same race or ethnicity, do not differ in head size.

\section{Conclusion}

There is a statistically significant difference between the cephalic index of the participants from South India and North East India. Mean, and Standard Deviation showed that SouthIndians weremore Mesocephalic, and Northeast Indians were moreBrachycephalic. MannWhitney $U$ test showed this differenceas statistically significant. Observing the frequency, Dolichocephalics and Mesocephalics were more in South India, and Brachycephalics and Hyperbrachycephalics were more in North East India. Hence, people from the South are larger in head size, compared to the North East. However, the cephalic index did not differ concerning gender.

Considering the geographical regions, the sample is small and not representative. Generalizations may be made comparing the present findings with those of the previous. Hence it contributes to the current literature, despite various limitations.

\section{Ethics approval and consent to participate.}

Prior to data collection, informed written consent was taken from the participants. The meaning, relevance, and purpose of the study were explained to them.

Competing Interests: The authors declare that they have no competing interests

\section{Author's contributions}

Both the authors have significantly contributed to data collection, analysis, preparing the manuscript, and approving the final version.

Acknowledgments: The authors acknowledge Mr. Manish Mishra, Assistant Professor, Department of Forensic Science, JAIN (Deemed-to-be University), Bangalore and Mr. Vichar Mishra, Assistant Professor, Department of Forensic Science, JAIN (Deemed-to-be University), Bangalore for their constant support and guidance.

\section{References}

1. Ilayperuma I. Evaluation of Cephalic Indices: A Clue for Racial and Sex Diversity. Int $J$ Morphol. 2011;29(1):112-117. doi:10.4067/s071795022011000100019

2. Seema, Verma P. The Study of Cephalic Index in North Indian Population. Int $J$ Morphol. 2016;34(2):660-664. doi:10.4067/s071795022016000200038

3. Franco FCM, de Araujo TM, Vogel CJ, Quintão CCA. Brachycephalic, dolichocephalic and mesocephalic: Is it appropriate to describe the face using skull patterns? Dental Press J Orthod. 2013;18(3):159-163. doi:10.1590/S217694512013000300025

4. Collett AR, West VC. Terminology of facial morphology in the vertical dimension. Aust Dent J. 1993;38(3):204-209. doi:10.1111/j.1834-7819.1993.tb03065.x

5. Farkas LG, Katic MJ, Forrest CR. International Anthropometric Study of Facial Morphology in Various Ethnic Groups/Races. J Craniofac Surg. 2005;16(4):615-646. doi:10.1097/01. scs.0000171847.58031.9e

6. Shah G.V; Jadhav H.R. The Study of Cephalic index in Students of Gujarat. J Anat Soc India. 2004;53(1):25-26.

7. S MAKBSSBAP. The study of cephalic index in Punjabi students. J Punjab Acad Forensic Med Toxicol. 2009;9:66-70.

8. Yagain VK, Pai SR, Kalthur SG, Chethan P, Hemalatha I. Study of Cephalic Index in Indian Students. Int $J$ Morphol. 2012;30(1):125-129. doi:10.4067/s0717-95022012000100022

9. Orish CN. Cephalic Index in Sexual Dimorphism and Racial Diversity: A Mini Review. MOJ 
Anat Physiol. 2018;5(1):23-26. doi:10.15406/ mojap.2018.05.00159

10. R N, Shukla AK, V.V SP. An ultrasonographic evaluation of foetal cephalic index. $J$ Evid Based Med Healthc. 2016;3(42):2059-2063. doi:10.18410/jebmh/2016/459

11. Mishra M, Tiwari A, Naik D. Study of cephalic index in Vindhya region of Madhya Pradesh. Int J Med Sci Public Heal. 2014;3(12):1464. doi:10.5455/ijmsph.2014.120920141

12. Shema K. Nair, Vaibhav P. Anjankar, Sandeep Singh, Maninder Bindra DK, Satpathy. The Study of Cephalic Index of Medical Students of Central India. Asian J Biomed Pharm Sci. 2014;4(28):4850.

13. Patro DS, Sahu DR, Rath DS. Study of cephalic index in Southern Odisha Population. IOSR J Dent Med Sci. 2014;13(1):41-44. doi:10.9790/085313174144

14. Salve VM, Thota NR, Patibandla A. The Study of Cephalic Index of Andhra Region (India). Asian J Med Sci. 2011;2(1):53-55. doi:10.3126/ajms. v2i1.3385

15. Kumari K, Babu $\mathrm{P}$, Kumari $\mathrm{P}$, Nagamani $\mathrm{M}$. A study of cephalic index and facial index in Visakhapatnam, Andhra Pradesh, India. Int $J$ Res Med Sci. 2015;3(3):656. doi:10.5455/2320-6012. ijrms20150324

16. S. Byhnadaorili, Kriti Gupta, Priyanka Nerwal, A. K. Gupta, M. Mishra LK. Variation in features of cephalic index among seven different tribal population of northeastern states of India. Int $J$ Chem Stud. 2018;6(2):3440-3445.

17. Uttekar K, Gupta DS, Andani R, Kubavat DM, Nagar SK, Varlekar P. Study of Cephalic Index in South Gujarat. 2013;8(2):87-89.

18. Ghosh SM. A study of cephalic index among the young age group of West Bengal in relation to sex and geographical factors. Indian J Basic Appl Med Res. 2018;7(3):239-245.

19. Manandhar B. Cephalic Index among Nepalese Medical Students. Orthod J Nepal. 2018;7(2):2023. doi:10.3126/ojn.v7i2.20159

20. Lobo SW, Chandrashekhar TS, Kumar S. Cephalic index of Gurung community of Nepal - An anthropometric study. Kathmandu Univ Med J. 2005;3 no. 3(11):263-265.

21. Bhasin MK. Indian Anthropology: Racial, Ethnic, Religious, and Linguistic Elements in Indian Population.; 2007.

22. Bharati S, Som S, Bharati P, Vasulu TS. Climate and head form in India. Am J Hum Biol. 2001;13(5):626634. doi:10.1002/ajhb.1101

23. Beals KL. Head form and climatic stress. Am J Phys Anthropol. 1972;37(1):85-92. doi:10.1002/ ajpa. 1330370111

24. Kobyliansky E. Changes in cephalic morphology of israelis due to migration. J Hum Evol. 1983;12(8):779-786. doi:10.1016/S00472484(83)80135-3 